\title{
A case report of de novo hepatocellular carcinoma after living donor liver transplantation
}

\author{
Songfeng $Y^{1,2,3}$, Hua Guo ${ }^{1,2,3}$, Li Zhuang ${ }^{1,2,3}$, Jun $\mathrm{Yu}^{1,2,3}$, Sheng Yan ${ }^{1,2,3}$, Min Zhang ${ }^{1,2,3}$, Weilin Wang ${ }^{1,2,3}$ \\ and Shusen Zheng ${ }^{1,2,3^{*}}$
}

\begin{abstract}
Post-transplant malignancy is the major cause of later death of recipients after liver transplantation. Tumor recurrence after liver transplantation for patients with hepatocellular carcinoma in the end stage of cirrhosis has been frequently encountered. However, de novo hepatocellular carcinoma originating from the liver allograft has only rarely been reported. Here we reported a case of de novo hepatocellular carcinoma developed 2 years after living donor liver transplantation for hepatitis B-related liver cirrhosis with viral YMDD mutation. To the best of our knowledge, this is the first report of de novo hepatocellular carcinoma in a liver graft with recurrent hepatitis B virus infection after liver transplantation for hepatitis B-related liver cirrhosis with YMDD mutation. Moreover, the de novo cancer first presented as a lung mass with minimal liver involvement and was obscured by a pulmonary fungal infection.
\end{abstract}

Keywords: De novo hepatocellular carcinoma, Liver transplantation, Living donor liver transplantation, Hepatitis B recurrence, YMDD mutation

\section{Background}

Liver transplantation (LTx) is the sole curative strategy option for end-stage liver diseases. Transplant recipients are thought to have increased risk of developing malignancies due to their lifelong immunosuppressant requirement. This has become a major cause of late mortality after LTx [1]. Carcinomas occurring in transplant recipients after LTx have been increasingly reported. Tumor recurrence after LTx for hepatocellular carcinoma (HCC) in end-stage liver cirrhosis is frequently encountered, especially with advanced HCC patients [2]. However, de novo HCC originating from liver allograft in a patient who received LTx for benign disease has only rarely been reported. To date, there have only been 11 cases of de novo HCC after LTx, reported in 8 papers in the literature [3-11]. In this paper, we report an additional case of de novo $\mathrm{HCC}$ developed after liver graft in the setting of

\footnotetext{
* Correspondence: shusenzheng@zju.edu.cn

${ }^{1}$ Division of Hepatobiliary and Pancreatic Surgery, Department of Surgery, First Affiliated Hospital, School of Medicine, Zhejiang University, Hangzhou 310003, China

${ }^{2}$ Key Laboratory of Combined Multi-Organ Transplantation, Ministry of Public Health, First Affiliated Hospital, School of Medicine, Zhejiang University, Hangzhou 310003, China

Full list of author information is available at the end of the article
}

hepatitis B (HBV) recurrence after living donor liver transplantation (LDLT) for HBV-related end-stage liver cirrhosis with viral YMDD mutation. To the best of our knowledge, this is the first report of de novo HCC in a liver graft with HBV recurrence after LTx for HBV-related liver cirrhosis with YMDD mutation. Moreover, the de novo tumor first presented as a lung mass with minimal liver involvement, and was obscured by a pulmonary fungal infection.

\section{Case presentation}

A 36-year-old man with decompensate hepatitis-Brelated cirrhosis underwent LDLT in our hospital on 23 June 2009. His younger brother, who was virus negative and had no evidence of tumor, donated the right lobe of his liver. The patient was hepatitis $B$ surface antigen (HBsAg), hepatitis B E antigen ( $\mathrm{HBeAg}$ ) and hepatitis B core antibody $(\mathrm{HBcAb})$ positive. The serum tests at the time of hospitalization showed that his HBV-DNA copy level was $2 \times 10^{8} / \mathrm{L}$ accompanied by YMDD mutation (rtM204I). Because the patient had a 3-year history of lamivudine treatment, adefovir was then added on for treatment; 1 month later the serum HBV-DNA level decreased to $1 \times 10^{4} / \mathrm{L}$ and he underwent LDLT. Preoperative

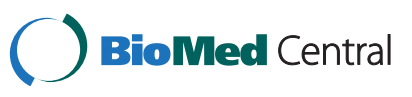


ultrasonography, computed tomography and MRI all ruled out the presence of tumor. Histopathology of the explanted liver also showed no evidence of malignancy, but micronodular cirrhosis with lymphocytic infiltration in portal tracts and moderate steatosis in the cirrhotic nodules was seen. After LDLT, the patient received an immunosuppressive strategy consisting of tacrolimus, mycophenolate mofetil and prednisone. For antivirus treatment as well as prophylaxis of HBV recurrence, a combination of add-on adefovir plus lamivudine and hepatitis B immune globulin was used according to our protocol [12]. Serum HBsAg was continually negative and hepatitis B surface antibody (HBsAb) positive on multiple tests post transplantation until 1.5 years later, when $\mathrm{HBsAg}$ was detected and remained positive for the remainder of his follow-up sessions. At 2 years after LDLT, the patient complained of cough with fever. A thoracic computed tomography scan showed a lower left lung infection with a nodule in the hilum of the left lung; bronchofibroscopic biopsy of the same confirmed a bulk Aspergillus infection (Figure 1). After 2 weeks of antifungal treatment, however, his symptoms were not alleviated. Further ultrasonography and MRI showed a small nodule that was only $0.7 \mathrm{~cm}$ in diameter in segment VI of the allograft (Figure 2). At the same time, serum tests showed his $\alpha$-fetoprotein (AFP) level was $400 \mathrm{ng} / \mathrm{ml}$ and a HBV-DNA copy test was positive. Fine needle aspiration biopsies were performed immediately for the nodule in the liver as well as a second time for the lung mass. Immunostaining for both specimens showed hepatocyte (+), AFP $(+)$, thyroid transcription factor 1 (TTF-1) $(-)$ and surfactant protein A (SPA) (-) indicating HCC (Figure 3). Thus, the diagnosis was HCC with lung metastasis with concurrent fungal infection. At the time of diagnosis, the patient had normal liver function. Therefore, his dose of tacrolimus was decreased by one-third and mycophenolate mofetil (MMF) maintained, but prednisone stopped. He underwent radiofrequency ablation for HCC in the liver and radiotherapy for the lung metastasis. At 3month follow-up, his liver imaging screen was clear. However, more nodules were found in the lung, suggesting uncontrolled metastasis. Our patient died from respiratory failure due to rapid progression of the lung metastases 4 months later.

\section{Discussion}

In the last few decades, increasing numbers of patients have been undergoing LTx worldwide. Owing to the maintenance therapy of immunosuppressive agents, the survival of transplant patients has greatly improved. However, an increased risk of de novo malignancies remains one of the major long-term complications after LTx. Potential factors related to de novo malignancies following LTx have been proposed as viral infection, long-term immunosuppressive therapy, longer survival of transplanted patients and possible malignant gene transfer from donors $[13,14]$. The reported predominant posttransplant de novo malignancies are post-transplantation lymphoproliferative disorder (PTLD) and skin tumors [15]. Other disorders such as gastric cancer, colorectal cancer, breast cancer and so on have also been reported [16,17]. Developing HCC after LTx most often happens in patients who have HCC before transplantation. Such cases are considered as HCC recurrence and have become a serious problem after LTx for HCC recipients. However, for nontumor recipients, de novo occurrence of HCC is extremely rare, with only 11 cases reported in recent years [3-11]. In

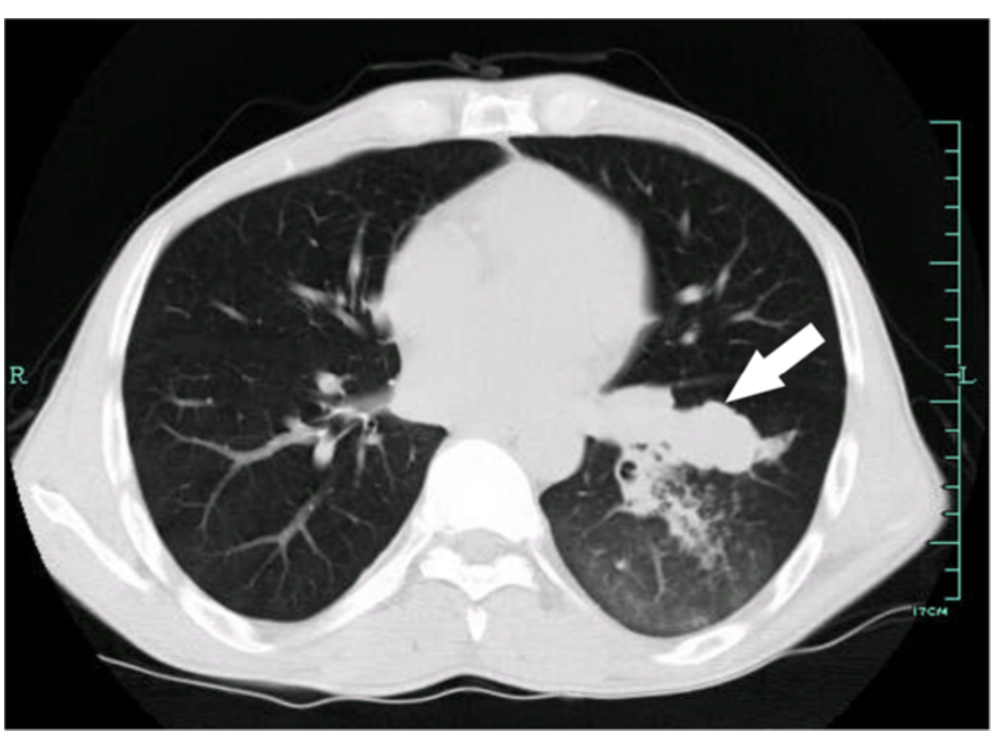

Figure 1 Thoracic computed tomography 2 years after living donor liver transplantation. The white arrow shows a nodular in the hilum of the left lung with the patchy shadow indicating pulmonary infection. 


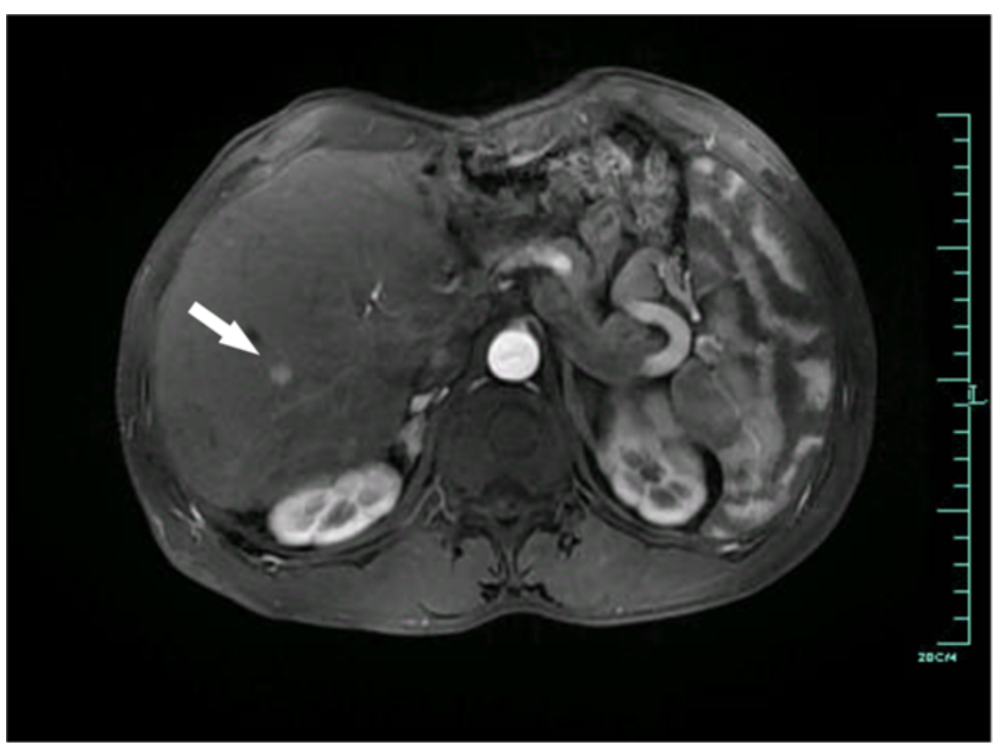

Figure 2 Artery phase of enhanced abdominal MRI 2 years after living donor liver transplantation. The white arrow indicates a 0.7-cm nodule of hepatocellular carcinoma (HCC) with arterial enhancement in segment VI of the allograft.

those cases, HCC developed from 3 to 22 years after the patient had received liver transplantation for end-stage liver diseases (HBV-related cirrhosis in four patients, HCV-related cirrhosis in four patients, alcoholic cirrhosis in two patients and Budd-Chiari syndrome in one patient). The present work reports a case of de novo HCC in the setting of HBV recurrence after LDLT for HBV-related cirrhosis.

Though the exact carcinogenic mechanisms are unknown, the etiology of HCC is strongly associated with cirrhosis of any cause, but is most related to chronic HBV or HCV infection [18]. Most of the reported de novo HCC cases were related to recurrent cirrhosis, either alcohol or viral related due to recurrent HBV or HCV infection [3,4,7,8]. Morita et al. reported a case of de novo $\mathrm{HCC}$ in a patient with sustained clearance of HCV after LDLT. Though cirrhosis had become established due to the HCV flare-up at 3 years after LDLT, successful clearance was obtained by treatments thereafter [11]. In the present case, HBV recurrence had also occurred prior to the diagnosis of de novo HCC. Faria et al. have suggested that pretransplant HBV-DNA viral load was positively associated with HBV recurrence at a median recurrence time of 15 months after transplantation despite receiving hepatitis $\mathrm{B}$ immunoglobulin, lamivudine and/or adefovir [19]. Our patient had a high load of HBV virus with YMDD mutation when he underwent LTx. Entecavir and tenofovir are newer antiviral drugs for HBV. Previous rescue therapy for chronic lamivudineresistant HBV included switching to entecavir and adding

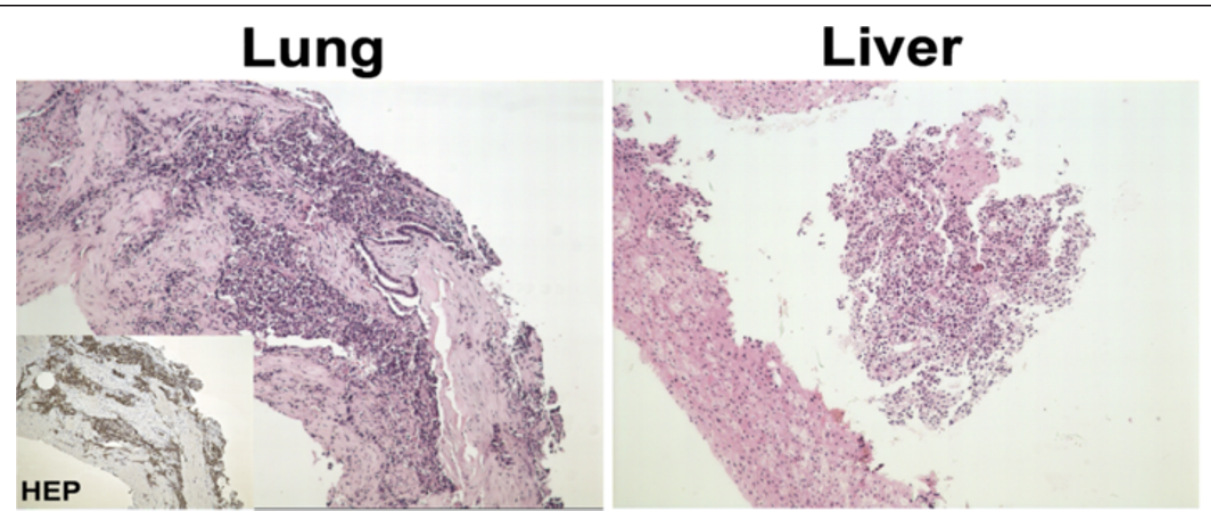

Figure 3 Histopathological staining of fine needle aspiration biopsy for nodules in lung and liver (original magnification 100x). The inset shows positive immunostaining for hepatocytes of the lung nodule biopsy. Immunostaining for both specimens indicated hepatocytes (+), a-fetoprotein (AFP) (+), thyroid transcription factor 1 (TTF-1) (-) and surfactant protein A (SPA) (-) (data not shown). HEP: hepatocyte. 
adefovir or tenofovir. The lamivudine selected rtM204I/V mutant is part of the entecavir resistance profile and the tenofovir-lamivudine combination resistance profile [20]. At present, switching to entecavir is not recommended for rescue therapy of lamivudine-resistant HBV. Though individual data showed that tenofovir had good efficacy in blocking viral replication in HBV patients with lamivudineresistant mutants [21], it has not been approved for HBV in China. A systemic review showed that lamivudine plus adefovir combined treatment was more effective and produced longer-lasting effects than other drugs to date [22]. Therefore, we applied adefovir add-on lamivudine antivirus treatment and the HBV-DNA copy level in our patient decreased dramatically. HBV was transiently cleared after transplantation and regular prophylaxis therapy was given, however, the patient still developed recurrent HBV infection 1.5 years after LDLT. Though the underlying mechanism was not clear, it is possible that the HBV recurrence could be attributed to the positive HBV-DNA viral load before transplant. This was also considered to be strongly associated with the HCC occurrence thereafter.

When considering de novo $\mathrm{HCC}$, the time period from LTx to the diagnosis of de novo HCC is of interest. Reports in the literature show that most recurrent $\mathrm{HCC}$ occurred shortly after LTx, whereas de novo HCC usually develops several years after recurrent HBV or HCV infection; enough time to develop cirrhosis. According to the previously reported cases, the earliest cases of de novo HCC occurred 3 years after LTx, and the latest occurred 22 years after LTx. However, in the present case, de novo HCC developed only 2 years after LDLT/6 months after recurrent HBV. This was a rather short time for de novo HCC after LTx. Recently, a more precise genomic allelotyping method has been applied for distinguishing recurrent and de novo HCC after LTx. Multiple polymerase chain reaction amplification of the highly polymorphic short tandem report DNA sequences extracted from tumor tissues can effectively discriminate between donor and recipient origin $[7,10,11]$. This is extremely useful in cases where primary HCC existed before LTx [11,23]. However, some reports considered de novo $\mathrm{HCC}$ based on the clinical evidence rather than this method $[5,6,8]$. Use of this method was hampered in the present case due to technical reasons.

Neither pretransplant image studies nor intensive histopathology of the explanted liver revealed any evidence of malignancy existing before LTx. Moreover, evidence was clear that de novo HCC can develop in a short time after LTx. Vernadakis et al. reported a case of de novo HCC diagnosed 3 years after LTx without cirrhosis or any other clear reasons [10]. Indeed, HBV infection can lead to HCC in the absence of cirrhosis [18]. Therefore, it is not surprising that the recurrent $\mathrm{HBV}$ infection in the present case may be associated with the unusually rapid development of HCC without cirrhosis. However, viral YMDD mutation might also be associated with HCC development. Hosaka et al. reported that HCC could develop in HBV patients receiving adefovir add-on lamivudine treatment independently related to the YMDD mutation [24]. Thus, the positive HBV-DNA viral load and YMDD mutation before transplantation increased the risk of developing HBV recurrence and consequent elevated carcinogenesis after LTx under immunosuppression therapy in the present case. Taken together, though lacking direct genetic evidence of donor origin, we did observe HCC shortly after LTx that might be attributable to the HBV recurrence and YMDD mutation. To the best of our knowledge, this is the first report of de novo HCC in a liver graft with HBV recurrence after LTx for HBV-related liver cirrhosis with YMDD mutation.

Of interest, the present case of de novo HCC first presented as a lung mass followed by the detection of a minimal liver nodule that was only $7 \mathrm{~mm}$. The patient only showed symptoms of pulmonary infection during the initial period. The existence of a pulmonary fungal infection obscured the primary diagnosis because fungal infection usually presents as a lung mass. We could not determine whether the fungal infection occurred before or as a result of obstruction of bronchi by the lung metastasis. Nevertheless, the fungal infection suggested a poor immunocompromised situation in the lung. Therefore, we presume that it might have contributed to the early lung metastasis despite a minimal liver involvement, thus compromising the therapeutic effect.

\section{Conclusions}

De novo $\mathrm{HCC}$ is a rare finding in post-LTx patients and may be associated with recurrent HBV infection. Patients with positive HBV-DNA loads before LTx, especially those with pre-existing YMDD mutations, also have a higher risk of developing de novo HCC. In addition, unexplained fungal infection may also warrant evaluation as a possible cause of HCC development.

\section{Consent}

Written informed consent was obtained from the patient's next-of-kin for publication of this case report and any accompanying images. A copy of the written consent is available for review by the Editor-in-Chief of this journal.

\footnotetext{
Abbreviations

AFP: a-Fetoprotein; HBsAg: Hepatitis B surface antigen; HBV: Hepatitis B virus; HCC: Hepatocellular carcinoma; HCV: Hepatitis C virus; LDLT: Living donor liver transplantation; LTx: Liver transplantation.
}

\section{Competing interests}

The authors declare that they have no competing interests. 


\section{Authors' contributions}

YS reviewed the data and literature and wrote the main manuscript. GH collected the patient data. ZL, YJ, YS and ZM were responsible for treatment of the patient. WW and ZS contributed to revising the manuscript. All authors have read and approved the final manuscript.

\section{Acknowledgments}

The authors thank Dr Jun Li and Dr Xiaodong Teng from the Department of Pathology in our hospital for their kind work on the pathology in this paper. This study was supported by the National S\&T Major Project (No. 2012ZX10002017).

\section{Author details}

${ }^{1}$ Division of Hepatobiliary and Pancreatic Surgery, Department of Surgery, First Affiliated Hospital, School of Medicine, Zhejiang University, Hangzhou 310003, China. ${ }^{2}$ Key Laboratory of Combined Multi-Organ Transplantation, Ministry of Public Health, First Affiliated Hospital, School of Medicine, Zhejiang University, Hangzhou 310003, China. ${ }^{3}$ Key Laboratory of Organ Transplantation, Zhejiang Province, Hangzhou 310003, China.

Received: 18 February 2013 Accepted: 27 July 2013

Published: 6 August 2013

\section{References}

1. Herrero ال I: De novo malignancies following liver transplantation: impact and recommendations. Liver Transp/ 2009, 15(Suppl 2):S90-S94.

2. Yao FY: Liver transplantation for hepatocellular carcinoma: beyond the Milan criteria. Am J Transplant 2008, 8:1982-1989.

3. Torbenson M, Grover D, Boitnott J, Klein A, Molmenti E: De novo hepatocellular carcinoma in a liver allograft associated with recurrent hepatitis B. Transplant Proc 2005, 37:2205-2206.

4. Saxena R, Ye MQ, Emre S, Klion F, Nalesnik MA, Thung SN: De novo hepatocellular carcinoma in a hepatic allograft with recurrent hepatitis C cirrhosis. Liver Transp/ Surg 1999, 5:81-82.

5. Levitsky J, Faust TW, Cohen SM, Te HS: Group G streptococcal bacteremia and de novo hepatocellular carcinoma after liver transplantation. Liver Transp/ 2002, 8:572.

6. Croitoru A, Schiano TD, Schwartz M, Roayaie S, Xu R, Suriawinata A, Fiel MI: De novo hepatocellular carcinoma occurring in a transplanted liver: case report and review of the literature. Dig Dis Sci 2006, 51:1780-1782.

7. Flemming P, Tillmann HL, Barg-Hock H, Kleeberger W, Manns MP, Klempnauer J, Kreipe HH: Donor origin of de novo hepatocellular carcinoma in hepatic allografts. Transplantation 2003, 76:871-873.

8. Kita Y, Klintmalm G, Kobayashi S, Yanaga K: Retransplantation for de novo hepatocellular carcinoma in a liver allograft with recurrent hepatitis $B$ cirrhosis 14 years after primary liver transplantation. Dig Dis Sci 2007, 52:3392-3393

9. Sotiropoulos GC, Frilling A, Molmenti EP, Brokalaki El, Beckebaum S, Omar OS, Broelsch CE, Malagó M: De novo hepatocellular carcinoma in recurrent liver cirrhosis after liver transplantation for benign hepatic disease: is a deceased donor re-transplantation justified? Transplantation 2006, 82:1112.

10. Vernadakis S, Poetsch M, Weber F, Treckmann J, Mathe Z, Baba HA, Paul A, Kaiser GM: Donor origin de novo HCC in a noncirrhotic liver allograft 3 years after liver transplantation. Transpl Int 2010, 23:341-343.

11. Morita K, Taketomi A, Soejima Y, Ikegami T, Fukuhara T, Iguchi T, Nagata S, Sugimachi K, Gion T, Shirabe K, Maehara Y: De novo hepatocellular carcinoma in a liver graft with sustained hepatitis $C$ virus clearance after living donor liver transplantation. Liver Transp/ 2009, 15:1412-1416.

12. Zheng S, Chen Y, Liang T, Lu A, Wang W, Shen Y, Zhang M: Prevention of hepatitis $B$ recurrence after liver transplantation using lamivudine or lamivudine combined with hepatitis B Immunoglobulin prophylaxis. Liver Transp/ 2006, 12:253-258.

13. Fung JJ, Jain A, Kwak EJ, Kusne S, Dvorchik I, Eghtesad B: De novo malignancies after liver transplantation: a major cause of late death. Liver Transp/ 2001, 7:S109-S118.

14. Dantal J, Soulillou JP: Immunosuppressive drugs and the risk of cancer after organ transplantation. N Engl J Med 2005, 352:1371-1373.

15. Penn I: Posttransplant malignancies. Transplant Proc 1999, 31:1260-1262.

16. Park HW, Hwang S, Ahn CS, Kim KH, Moon DB, Ha TY, Song GW, Jung DH, Park GC, Namgoong JM, Yoon SY, Park CS, Park YH, Lee HJ, Lee SG: De novo malignancies after liver transplantation: incidence comparison with the Korean cancer registry. Transplant Proc 2012, 44:802-805.

17. Shimizu T, Hayashi M, Inoue Y, Komeda K, Asakuma M, Hirokawa F, Miyamoto $Y$, Tanigawa N, Uchiyama K: A case of gastric cancer after living donor liver transplantation. Ann Transplant 2012, 17:122-126.

18. Nissen NN, Martin P: Hepatocellular carcinoma: the high-risk patient J Clin Gastroenterol 2002, 35:S79-S85.

19. Faria LC, Gigou M, Roque-Afonso AM, Sebagh M, Roche B, Fallot G, Ferrari TC, Guettier C, Dussaix E, Castaing D, Brechot C, Samuel D: Hepatocellular carcinoma is associated with an increased risk of hepatitis $B$ virus recurrence after liver transplantation. Gastroenterology 2008, 134:1890-1899. quiz 2155.

20. Bartholomeusz A, Locarnini SA: Antiviral drug resistance: clinical consequences and molecular aspects. Semin Liver Dis 2006, 26:162-170.

21. van der Eijk AA, Hansen BE, Niesters $H G$, Janssen $H L$, van de Ende $M$ Schalm SW, de Man RA: Viral dynamics during tenofovir therapy in patients infected with lamivudine-resistant hepatitis B virus mutants. J Viral Hepat 2005, 12:364-372.

22. Sheng YJ, Liu JY, Tong SW, Hu HD, Zhang DZ, Hu P, Ren H: Lamivudine plus adefovir combination therapy versus entecavir monotherapy for lamivudine-resistant chronic hepatitis B: a systematic review and meta-analysis. Virol J 2011, 8:393.

23. Mas VR, Maluf DG, Dumur Cl, Archer KJ, Yanek K, Jackson-Cook C, Fisher RA: Molecular techniques for identifying HCC origin and biology after orthotopic liver transplantation. Diagn Mol Pathol 2006, 15:90-94.

24. Hosaka T, Suzuki F, Kobayashi M, Hirakawa M, Kawamura Y, Yastuji H, Sezaki H, Akuta N, Suzuki Y, Saitoh S, Arase Y, Ikeda K, Miyakawa Y, Kumada H: Development of HCC in patients receiving adefovir dipivoxil for lamivudine-resistant hepatitis B virus mutants. Hepatol Res 2010, 40:145-152

doi:10.1186/1477-7819-11-176

Cite this article as: Yu et al:: A case report of de novo hepatocellular carcinoma after living donor liver transplantation. World Journal of Surgical Oncology 2013 11:176.

\section{Submit your next manuscript to BioMed Central and take full advantage of:}

- Convenient online submission

- Thorough peer review

- No space constraints or color figure charges

- Immediate publication on acceptance

- Inclusion in PubMed, CAS, Scopus and Google Scholar

- Research which is freely available for redistribution

Submit your manuscript at www.biomedcentral.com/submit
C) Biomed Central 